\title{
CARCELES PARA LA TOLERANCIA CERO: CLAUSURA DE POBRES, Y SEGURIDAD DE CIUDADANOS
}

\author{
MARÍA EMILIA TIJOUX*
}

\begin{abstract}
He querido que estos personajes sean oscuros; que nada los haya predispuesto para algún brillo; que no estén dotados de ninguna de esas grandezas que se establecen y se reconocen: las del nacimiento, de la fortuna, de la santidad, del heroísmo o del genio; que pertenezcan a esos miles de existencias que están destinadas a pasar sin dejar huella; que haya en sus desgracias, en sus pasiones, en sus amores, $y$ en sus odios algo de gris y de ordinario para la mirada de lo que se estima digno de ser contado.

(FOUCAULT, 1994:12-29)
\end{abstract}

\section{INTRODUCCIÓN}

EL TEMOR INVADE LAS ciudades modificando tanto las políticas de Estado como el rostro de la sociedad. Múltiples denuncias sobre actos de «violencia urbana» movilizan los servicios policiales en torno a una intensa vigilancia de los sectores populares, a la vez que observamos cómo se reprime a la venta ambulante, los actos molestos y desviados de los jóvenes, y la presencia de vagabundos y niños en las calles. La causa del temor está claramente ubicada en la presencia sospechosa de personas que por su misma existencia develan su condición de vida: vagabundos, mendigos, gitanos, jóvenes, extranjeros rechazados, to-

* $\quad$ Licenciada en Filosofía, Maestra en Ciencias Sociales. Docente Universidad ARCIS, Santiago. E-mail: bise@byo.cl. 
das características del mundo de la pobreza. Los jóvenes pobres son entre todos, el principal blanco al que apuntan las políticas represivas - y de defensa - implementadas con el objetivo de mantener segura la vida económica y social. La delincuencia juvenil, la presencia de barras bravas, las manifestaciones estudiantiles y hasta los encuentros culturales, son algunos de los problemas que aparecen explicando la sensación de inseguridad de los ciudadanos.

El proceso estigmatizador, iniciado con fuerza desde el siglo XVIII contra las clases peligrosas producto de la industrialización, se afina y se focaliza en grupos donde hay que aplicar la mano fuerte del Estado. La pobreza, al quedar claramente circunscrita desde su «posible» peligrosidad, será el marco que llevará a sus principales protagonistas hasta el encierro en la cárcel y en centros especializados que, antes de la mayoría de edad, se utilizan como lugares de observación y diagnóstico de sus conductas.

Este miedo a la pobreza se generaliza en diversos países del mundo junto con la globalización, mientras los medios de comunicación masiva se encargan de difundirlo cotidianamente desde imágenes $\mathrm{y}$ hechos que fundamentan y legitiman los discursos «sobre y contra la violencia», llenando las principales páginas de periódicos y de tiempo televisivo. ${ }^{1}$ Hábiles especialistas de las más variadas disciplinas confluyen para unirse a esta suerte de cruzada, exponiendo incidentes cotidianos — que siempre han sucedido- que ahora se vuelven más sentidos por el común de la sociedad. Esta verdadera producción, entendida en su sentido más espectacular, consigue ocultar en las bambalinas de su escenario, los reales problemas que la sociedad tiene, como ocurre con el rol de un Estado que se aparta y se desentiende cada vez más de lo social.

La diversidad de estos discursos conviene buscarla en conceptos que no han surgido espontáneamente ni vienen «dados» en la realidad, sino que vienen inscritas en: «una vasta constelación discursiva de términos y de tesis venidas de Norteamérica sobre el crimen, la

1 En los últimos días se ha pretendido un cierto cambio de la situación. «Informe Especial», muestra en la emisión del jueves 11 de octubre 2001 las «dos caras» de la Población La Legua: los malos perseguidos con gran brutalidad policial, y los buenos que rodean la figura de Mariano Puga y las comunidades cristianas. La gran justificación es la demanda de los pobladores por ser considerados como personas y no ser excluidos por su lugar de vida. La «campaña» televisiva logra de esta manera calmar los ánimos y aumentar su raiting. 
violencia, la justicia, la desigualdad y la responsabilidad — del individuo, de la 'comunidad', de la colectividad nacional— que se insinúan poco a poco en el debate público y que deben lo esencial de su poder de convicción a su omnipresencia y al prestigio de sus iniciadores en el escenario internacional» (Wacquant, 1999:19).

Así se desarrolla un proceso en el que participan instituciones, personas y soportes discursivos para construir conjuntamente un sentido común penal que criminaliza la pobreza. La máquina que se mueve por detrás de ese sentido común penal, está movida por la ideología económica y social basada en el individualismo y que ahora traducida en lo jurídico, se cristaliza en un efectivo y eficiente dispo-sitivo de marketing ideológico que tiene impacto mundial.

\section{POBRES MALOS Y POBRES BUENOS}

El encierro es un buen modo de tratamiento político-social de la pobreza. Principalmente de los pobres malos, inhabilitados para la vida en sociedad, y a los que se intenta — difícilmente - tratar/curar con políticas sociales que aseguren el orden público y preserven el equilibrio económico de la sociedad. Desde fines del siglo XIX, este conjunto de prácticas (políticas) sirvió para atenuar los efectos de la doble revolución económica y política de fines del siglo XVIII (Castel, 1995). Desde entonces, el trabajo (sobre lo) «social», se ejerce principalmente sobre los pobres buenos, respetuosos del orden establecido por la dominación. Los pobres malos que no respetan las reglas de la armonía social deberán sufrir los castigos correspon-dientes a sus faltas. $^{2}$ Vale recordar que desde fines de la Edad Media hasta la Revolución Francesa se observará la dureza y la crueldad de castigos sobre pobres, mendigos y delincuentes, — todos confun-didos-. Con el paso del tiempo, el tratamiento de la pobreza oscilará entre la asistencia a los pobres más buenos y la represión de los pobres más malos

2 Al respecto vale considerar que Emilio Durkheim define al crimen sociológicamente como cualquier violación a las reglas, explicando que en sociedades (o segmentos) con una fuerte conciencia colectiva el acto de transgresión provoca una herida en toda la sociedad que se siente amenazada. Sólo la multiplicación de las sanciones y de los castigos (muchas veces crueles) podrá calmar esta inquietud. En la sociedad moderna e individualista, la conciencia colectiva se resquebraja, de ahí que recurra al derecho para igualar las penas. El encierro en la cárcel permitirá tranquilizar los ciudadanos que se sienten inseguros. 
que transgreden el orden. Al mismo tiempo aumenta el pauperismo y la desintegración del cuerpo social.

El encierro penal será la medida más usada en la clausura de pobres, y de incontrolables (locos, prostitutas, enfermos venéreos, vagabundos) en diversas instituciones. Clasificados por su noclasificación, deberán ser colocados en un lugar donde se depositen grupalmente. El encierro penal (confirmado en Francia en 1810), ordenará y codificará el encierro, transformando el mal en bien gracias a una cobertura jurídica «más justa», aunque siempre tratando el mal con el mal, por eso el castigo. La cárcel, a pesar de sus continuas pruebas de ineficacia, debe gran parte de su éxito a la función legitimadora de una vieja práctica que se convierte en la más usada por las sociedades occidentales. Los lugares miserables de las prisiones del mundo «recogen», a miles de pobres que esperan ser condenados o que purgan sus penas. Este modo de administración de la pobreza, explica cómo a pesar de sus «ilegalismos», ${ }^{3}$ la cárcel permanece en el tiempo, circunscribiendo la delincuencia en los pobres, y sobre todo encarnando en ellos, toda la delincuencia.

El artículo VII de la Declaración de los Derechos del Hombre de agosto de 1789 , señala que: «ningún hombre puede ser acusado, arrestado ni detenido, salvo en los casos determinados por la ley». Con esta declaración, los reformadores del siglo XVIII ponían (supuestamente) fin a la arbitrariedad y la crueldad de los castigos del Antiguo Régimen. Pero junto con ello y, preocupados por las consecuencias que los cambios ocurridos podían tener sobre la evolución política de la sociedad, consideraron dos importantes inconvenientes: los efectos carcelarios del «contagio» y las malas con-diciones de vida en las prisiones. Pero esos inconvenientes fueron rápidamente remediados: el riesgo de contagio se resolvió con el encierro en celdas individuales, y las críticas respecto de la insalubri-dad y las malas condiciones se enfrentó con el empuje modernizador que transformaba las prisiones y las instituciones encargadas del control. La dureza de la vida que los prisioneros sufrían durante las detenciones y el encierro se integraron además en un objetivo cuasi terapéutico inspirado en la penitencia y la redención cristianas: sufrir para pagar las culpas (Combessie, 2001:14-15). El trabajo cumple así una función expiato-

3 Michel Foucault se preguntaba sobre la perennidad de esta institución llena de «ilegalismos» que de cierta manera resume simbólicamente a las demás y dejan en la oscuridad aquellas que se debe o desea tolerar. 
ria, a la vez que sirve a los intereses humanistas de la necesidad del carácter público de las penas.

La prisión se instaura como un aparato que busca la transformación del malo en hombre de bien, desde un proceso que se aplica en virtud de un derecho penal reformado por leyes igualitarias, y que persigue modelar una humanidad mejor que la bárbara y arbitraria del Antiguo Régimen. El humanismo se erige como el mito fundador que explica la nueva forma de encierro, con un modelo que regularmente se renueva a la vez que oculta lo que realmente es: un dispositivo práctico, barato y discreto. Lo penal no es más que la vestidura que maquilla un proyecto que plantea una profunda reforma, ${ }^{4}$ y los cambios superficiales- sólo abolirán prácticas arbitrarias como las Lettres de cachet, beneficiando de este modo a importantes actores del mundo político o económico, pero no a las personas comunes que se castigaba con crueldad. El tormento se privatiza y se reglamentan las formas de ejecución con el objetivo de disminuir el tiempo y el dolor de los condenados. La humanización de la muerte — según la propuesta de J. I. Guillotin - se hará posible gracias al uso de un artefacto que evita el sufrimiento. De ese modo sólo sentirán «el frescor en la nuca».

El encierro penal como (antiguo) modo de administrar la pobreza responde a los objetivos que necesita el orden público, frente a la amenaza social en que la pobreza es percibida como criminó-gena. $^{5}$ Vale destacar a este respecto, los trabajos de investigadores, ${ }^{6}$ que han focalizado sus trabajos demostrando que la antigüedad y la permanencia del vínculo entre pobreza y criminalidad, es lo que ha legitimado el sentido común en torno a la primera. La opinión ${ }^{7}$ se fabrica sobre el origen socioeconómico de los detenidos que de toda evidencia perte-

$4 \quad$ Estos hechos se dan y se refuerzan tanto durante el Terror como durante el Segundo Imperio. Los tratamientos crueles no desaparecieron y más aún algunos fueron restablecidos por Napoleón I, como el castigo del «poing coupé». Los trabajos forzados y la pena de muerte permanecieron.

$5 \quad$ Ver en Durkheim: El suicidio y La división del trabajo social (último capítulo) donde hace referencia a este concepto.

6 Godefroy y Laffargue: «Pauvreté, crime et prison», en L'actualité sociale N¹94, La Documentation Francaise, 1992. También en su trabajo «Les couts du crime en France, les depenses de securité», Etudes et données penales $\mathrm{N}^{\circ} 66$, CESDIP.

7 Al respecto véase en Bachelard: La formación del espíritu científico: «La opinión piensa mal: ella no piensa: traduce sus necesidades en conocimiento. Designando los objetos por su utilidad, se prohibe conocerlos»; y en Bourdieu: Sociología y cultura: «La opinión pública no existe». 
necen a los sectores más excluidos de la sociedad si tomamos en cuenta que los prisioneros siempre son pobres. Sin embargo, — señalanno se debe confundir el resultado de un proceso social como la represión penal, que selecciona y clasifica a los individuos que encierra, con el vínculo causal que se construye entre status social y criminalidad. Tenemos que pensar que gran número de investigaciones adopta este enfoque que criminaliza a los pobres, de ahí que sus resultados estén siempre prácticamente anunciados. Las propuestas que se desprenden vienen ya decididas por la máquina política.

Entonces, que las cárceles estén llenas de personas pobres corresponde a una voluntad mayor. Parece normal que personas de estratos sociales superiores que cometen los mismos delitos que personas de sectores pobres no sean tratados del mismo modo que un pobre. $\mathrm{O}$ parece normal que personas de estratos superiores cometan delitos que corresponden al sector socioeconómico del que provienen: estafa, fraude al fisco, tráfico de influencias, por ejemplo. También parece normal que sus fechorías no sean «tan mal vistas». Luego, parece normal que en su corto paso por la cárcel sean objeto de mejor trato por parte de los funcionarios. Pero también parece normal que no permanezcan en la cárcel. No es ése su lugar.

En el año 1915, Domingo Pérez Fuentes escribía: ${ }^{8}$ «La escuela lombrosiana ha prestado un servicio inmenso i su influencia se hace notar ya en los sistemas penales. De aquí que es lógico que la represión sea proporcional al daño causado i que no es razonable el castigo que propone una pena fija». Las causas del delito para Pérez eran: «el ambiente social, la vagancia y la infancia abandonada». Esta segura afirmación sostiene que la pobreza excluida (pobre malos) es delincuente. Además agrega: «la delincuencia es una enfermedad, lo dice la ciencia i la esperiencia. El delincuente obra en virtud de una fuerza imperiosa e irresistible. La sociedad tiene el derecho i el deber de defenderse de los delincuentes; pero debe defenderse de ellos no solamente con el castigo que se resume en la venganza, sino con la piedad, con la curación benévola que debe darse a los enfermos. ¿Por qué no mata a la sociedad a todos los tuberculosos i sifilíticos i a tantos otros atacados de enfermedades incurables?».

El sufrimiento de los pobres se vuelve anecdótico. Los hechos

8 Pérez Fuentes: Sistema carcelario y prevención del delito, Imprenta Royal, Valparaíso, 1915. 
de dolor se repiten a la misma velocidad con que cambian los titulares de los diarios. En mayo de 2001 en el penal de Iquique, 26 jóvenes morían quemados. Las pesquisas buscaron las causas en primer lugar en los mismos reclusos: ellos mismos habían provocado su muerte: las habituales riñas, los desórdenes, las disputas internas eran posibles causas de la tragedia. Poco después se culpaba a los gendarmes y se indicaba la responsabilidad de dos de ellos en el hecho. Un tiempo después en algunas líneas de los diarios se podía leer la necesidad de un juicio a la administración de Gendarmería. La cárcel no era vetusta, había sido recién construida pensando en la seguridad de los detenidos. Sin embargo, los edificios nuevos (inteligentes) reaccionan inmediatamente con el fuego y el humo. El agua cae.

Dado que la sociedad se desinteresa y criminaliza las conductas de sus miembros improductivos o peligrosos para el orden social, los hechos que acontecen en las cárceles con consecuencia de muerte para los detenidos no provocan mayores críticas. Al contrario, se puede advertir en la opinión pública -inmediatamente después de las tragedias - , una cierta tranquilidad. Pareciera que la limpieza desde adentro pudiese terminar con la amenaza. Pero limpiar también por fuera se convierte en un asunto de Estado.

\section{TOLERANCIA CERO: EFICAZ REMEDIO PARA LA SEGURIDAD CIUDADANA}

Desde Washington y Nueva York en los años ochenta, se instala una nueva razón penal. Los organismos de Estado implementan políticas penales ultra represivas, con alta participación del sector privado, construyendo una nueva doxa punitiva. "Losing Ground», interesante libro de Charles Murray, ${ }^{9}$ se convierte en un verdadero catecismo de los luchadores contra la violencia social. El texto abre el camino para la popularización de discursos y de dispositivos represivos contra los «desórdenes» protagonizados por pobres.

El blanco de la crítica son los políticos que aparecen demasia-

$9 \quad$ Politólogo mediocre, ex gurú de Reagan, recibe 30 mil dólares para escribir durante dos años Losing Ground: American Social Policy, 1950-1980. Luego se hará una inmensa publicidad del libro con la participación de periodistas, burócratas, y especialistas. El Manhattan Institute realiza un simposio lanzándolo a la fama. Expertos en políticas públicas y especialistas de las Ciencias Sociales recibirán por su participación 1500 dólares y alojamiento en un lujoso hotel de Nueva York. 
do generosos, y por ello inducen a la degeneración moral. Loic Wacquant explica que la continuidad que se advierte en estas afirmaciones proviene de otro libro del mismo estilo: Wealth and Poverty de George Gilder, que hace un gran descubrimiento: el origen de la miseria norteamericana se encuentra en la anarquía familiar de los pobres, verdaderos clientes de un asistencialismo social que pervierte el deseo de trabajar, daña la familia patriarcal y erosiona el fervor religioso. Otro libro de Murray: Pursuit of Happines and Good Governemet acusa directamente al Estado como responsable. Pero no hay que olvidar la fama que tuvo con The Bell Curve escrito anteriormente junto al psicólogo de Harvard, Richard Herrnstein, donde intentó demostrar que las desigualdades raciales revelaban diferencias individuales y cognitivas, y que los éxitos universitarios, económicos y hasta familiares, estaban determinados por el coeficiente intelectual. Visto así, también lo estará la propensión al delito y a la cárcel.

Desde este suelo, la sociedad reacciona favorablemente y con gusto a las medidas propuestas, sobre todo si se trata de mantener el equilibrio económico y preservar la seguridad. A partir de estos «científicos» descubrimientos se arman las principales líneas de trabajo que hará de Nueva York el centro mundial de la difundida práctica de la «tolerancia cero», que perseguirá la delincuencia juvenil, los mendigos, los vagabundos, los niños de la calle, los vendedores ambulantes, con el fin de alejarlos de los centros urbanos. William Bratton, responsable de la seguridad del Metro de Nueva York y jefe de la Policía Municipal reorganizará su labor, ${ }^{10}$ advirtiendo claramente: «yo sé dónde está el enemigo».

Los enemigos de este experto son los «squeegee men» (gente que acosa los automovilistas), los pequeños vendedores de droga, las prostitutas, los vagabundos y los jóvenes graffiteros. Para luchar contra sus prácticas: trafico, ruidos molestos, amenazas, suciedad, ebriedad, la policía se valdrá de un sistema estadístico (COMPSTAT) que distribuye su acción a partir de informaciones precisas y actualizadas por las denuncias en cada comuna. Bratton va a dirigir la policía como un industrial, y declarará con orgullo que si lo quisiera podría comparar su staff con «cualquiera de la lista Fortune 500». La Tolerancia

10 Así pone en funcionamiento la teoría del libro de Kelling y Coles: Reparar las ventanas rotas, o cómo restaurar el orden y reducir el crimen en nuestras comunidades», (Traducción: M. E. Tijoux), Nueva York, The Free Press, 1996. 
Cero conocerá desde 1994, un inmenso éxito que se propagará rápidamente (comenzando por Inglaterra).

Pero el creador de este interesante plan no se limitó solamente a capacitar europeos. Su viaje se extendió por América Latina y llegó hasta Chile, donde nos entregó: «las principales directrices para enfrentar el problema de la delincuencia», ${ }^{11}$ abordando el éxito de las políticas de seguridad ciudadana implementadas en Estados Unidos. El seminario se denominó «Experiencias exitosas contra la delincuencia en una sociedad moderna», y dio cuenta de buena parte del libro de Kelling, autor de Fixing Broken Windows: restoring order and reducing crime in our communities, (o la política de reparar las ventanas rotas) que inspiró al famoso Rudolph Giulliani, Alcalde de Nueva York, para atacar con fuerza a la delincuencia.

Las conferencias, organizadas por el Instituto Libertad y Desarrollo, contaron con la participación de expertos norteamericanos: Carlos Medina del área educación del Manhattan Institute, Michel O’Connor de la planificación de seguridad y el propio Bratton, creador del plan. Sus preocupados homólogos fueron Cristian Larroulet director ejecutivo de Libertad y Desarrollo, Eugenio Guzmán, director político del mismo organismo, y Joaquin Lavín, Alcalde de Santiago. Todos intervinieron desde temáticas propias vinculadas a la escuela, la higiene, la vigilancia de la ciudad y los planes policiales especiales. ${ }^{12}$ La «Tolerancia Cero» prueba con éxito que un enfrentamiento duro de problemas menores como la ebriedad, el vagabundaje, la prostitución, la drogadicción, la vida en la calle, el rallado de graffitis, e incluso conductas como orinar y escupir en la vía pública, podría frenarse la delincuencia mayor.

Tomando en cuenta que en gran parte, el temor se construye

11 El Mercurio, Santiago, 6 de diciembre del 2000.

12 Medina presentó el proyecto norteamericano de escuelas públicas autónomas que integra a padres y profesores en un sistema burocrático centralizado con participación de sectores públicos y privados. Son escuelas abiertas para todos y evaluadas por sus resultados, de los cuales depende la autorización para funcionar. O’Connor, asesor de los alcaldes de Nueva York para enfrentar diversos problemas, explicó cómo la iluminación y el contrato de guardias de seguridad privados vestidos con llamativos uniformes (rojos encendidos), reparaban la ciudad pintando sobre los graffitis, además contrató más personal de limpieza destacándose la eficiencia de aquellos con antecedentes delictuales. Manhattan habría recobrado su plusvalía. Bratton por su parte, enfatizó la baja de la delincuencia gracias a la aplicación de planes especiales. 
justamente sobre estas situaciones, la idea de encararlas con rigor permitiría evitar que creciera. Los ciudadanos que han desertado del espacio público por miedo, podrían regresar siempre y cuando se consiga liberarlo del lumpen. El éxito del plan consiste entonces en crear una sensación de seguridad a partir de la detección de la falta más pequeña, ${ }^{13}$ construyendo una sólida relación de confianza entre la comunidad y la policía que trabajarían mancomunadamente, en lugar de la excesiva asignación de recursos a la policía, señala el famoso plan de las «Ventanas rotas» o «Tolerancia Cero». Simultáneamente, debe crearse una sensación de vigilancia y de presencia policial para los posibles transgresores. ${ }^{14}$ Los especialistas aseguraron, ante la preocupación manifestada por el costo de estas medidas, que se pueden aplicar en cualquier ciudad por muy limitados que sean sus recursos.

En una entrevista realizada a Pía Guzmán el sábado 2 de junio ante la pregunta de «si los presos están más seguros dentro o fuera del penal» (algunos días después del mortal incendio de Iquique), ella responde: «depende de dónde se mire: los delincuentes siempre se sienten más seguros en medio de su grupo de colegas y en la población, si ésta los apoya. Las víctimas y la sociedad se sienten seguras cuando ellos están en la cárcel». Luego entrega una interesante alternativa (actualmente practicada) para evitar la prisión: «El problema es que tenemos la cultura de convertir los hechos repudiables en delitos y éstos son sinónimos de prisión, sin considerar que hay otras sanciones igual de efectivas y socialmente más rentables, como el arresto domiciliario con pulsera electrónica para supervigilar el cumplimiento». ${ }^{15}$ No se trata aquí de ciencia-ficción, sino del sincero deseo de la diputada.

\section{DESEO DE ESCAPAR Y MODERNIZACIÓN DE LAS PRISIONES}

13 Tal como sucedió en el Metro de Nueva York, cuando luego de sancionar a los que no pagaban, a los que provocaban desórdenes y ruidos molestos, a los vagabundos, a los extranjeros, se redujeron los problemas.

14 El problema de la «violencia en los estadios» muestra la supuesta eficacia de un plan para controlarla: empadronamiento de las barras, prohibición de desplegar lienzos en la cancha, severos controles en los ingresos permitirían, gracias a la coordinación entre las autoridades del fútbol, el gobierno y la policía, terminar con esos actos. La ley deberá aplicarse a los futbolistas que inciten a desmanes.

15 El Mercurio, Santiago, 2 de junio del 2001. 
La osadía de los presos es una actitud que no cambia, y la idea de escapar de las cárceles continúa, tal como lo demuestra el reciente descubrimiento de túneles de treinta metros de extensión y cinco de profundidad en la ex-Penitenciaría de Santiago, lo que provocó gran preocupación en Gendarmería, sobre todo después de las medidas modernizadoras de seguridad recientemente adoptadas para evitar las fugas: barreras subterráneas adicionales a los muros, franjas de seguridad levantadas en la superficie y planchas de acero soldadas. Por otra parte, se equipó con diversos procedimientos de seguridad y de instalaciones de alta tecnología con circuitos cerrados de televisión, equipos de rayos $\mathrm{X}$ y arcos detectores, lográndose una disminución de las fugas junto con proyectar una gran reducción para el año 2006, con la construcción de una de las dos nuevas cárceles programadas. Se trata de un complejo penitenciario de gran envergadura que se levantará en los terrenos de FAMAE. Al mismo tiempo, con el traslado de los denominados «polos judiciales» a los terrenos de la nueva cárcel, se piensa evitar la posibilidad de escape.

Pero estos resguardos están muy lejos de contener los verdaderos sufrimientos de los detenidos. El 20 de septiembre, la muerte de Américo Jaramillo Cabrera, un joven de 17 años pone de nuevo sobre la mesa el debate acerca de las contradicciones que están a la base de las propuestas: ¿separar o no separar jóvenes de adultos? ¿Sigue la posibilidad del contagio? ¿ $\mathrm{O}$ acaso a los 17 años no se es adulto todavía? Parece que las muertes provocan aquella intención de ordenar lo que estaría desencajado del orden, cuestión de «humanizar» otra vez. Los ilegalismos a los que se refería Foucault son habituales. En Chile hay más de 550 jóvenes (menores según la ley) encerrados en cárceles de adultos, hecho que transgrede la legislación nacional vigente y los acuerdos internacionales. La ley, instrumento regulador tiene sus «olvidos», tal como sucede con la ley 19.343 del año 1995 que deja fuera a los menores de 18 años y menores de 16 declarados con discernimiento.

Hurgando en las responsabilidades por estas fallas se apunta una vez más al Estado. Visto que la gestión es deficiente, numerosas voces e intereses se alzan para considerar la aplicación de una lógica carcelaria que siga el modelo de la economía social de mercado. La inversión en un sistema penitenciario es socialmente muy rentable, y puede organizarse muy bien desde criterios como la segmentación de 
los reclusos según la edad, y la gravedad de los delitos, ${ }^{16}$ todos ellos considerados para reducir el contagio criminógeno. En este sentido, la rehabilitación también podría emerger como un buen producto derivado que se inspirara en el pleno empleo y la obtención de una mano de obra «cautiva» puesta al alcance de las expectativas privadas.

La cárcel es la medida y la pena del pobre, es maquinaria institucional para pobres, personas-objetivo que explican con su existencia las condiciones en que se desarrolla su detención y las expectativas que se tienen de ella. El detenido purga una pena que por definición debe ser penosa, lo suficientemente dura para que se logre el objetivo que el castigo contiene.

El mismo término «población penal» remite al concepto de «población», con toda la historia de estigma que conlleva. Por una parte va a referir a las características estructurales de los sectores de vida de los presos: arquitectura concentracionaria, lugares vetustos y húmedos, piezas pequeñas, hacinamiento, carencia de espacios verdes, lejanía de los centros de intercambios — entre otras - ; y por la otra, su sola pronunciación hará visible toda la subjetividad que encierra por la funcionalidad de su significación: flojera, maldad, desconfianza, promiscuidad, desajuste familiar, anarquía, ignorancia. La prisión tiene que ser miserable para acoger a miserables, y por ello a lo mejor se asemeja tanto a sus lugares de vida. En este marco, la miseria del interior debe ser tan o más miserable que la miseria exterior de sus barrios y sus viviendas.

Sigue planteado el problema: ¿para qué la cárcel? Si la pobreza de sus encerrados ha justificado durante tanto tiempo la propia condición de la prisión, ¿cómo se entiende la rehabilitación, la reinserción, la reintegración, todos los re que suponen la existencia de un estado anterior «normal»?.

La adopción de una política generalizada de criminalización de la pobreza se complementa con políticas sociales que pretenden beneficiar a un sector de pobres comprometidos a permanecer en la norma social. Política social y política penal se divisan como únicos horizontes posibles para quedarse en el mundo. La libertad se acomoda en esos límites, acurrucándose en las esquinas de la gran ciudad y en los rincones alejados donde se acumulan ordenadamente mínimas viviendas destinadas a lo básico.

16 Como la segmentación de los reclusos según edad, gravedad de delitos. El origen socioeconómico no se cuestiona, puesto que se sabe de la pobreza que los caracteriza. 
Parece que vale citar a Bourdieu cuando destaca que: «El neoliberalismo, 'teoría' originariamente desocializada y deshistorizada tiene hoy día más que nunca los medios para hacerse verdadera, empíricamente verificable» (Bourdieu, 1998:109). Un verdadero socialpanoptismo se ha desencadenado.

SANTIAGO, OCTUBRE DEL 2001

\section{BIBLIOGRAFÍA}

BACHelard, G. (1993): La formation de l'esprit scientifique. Paris: Ed. Librairie Philosophique.

BourdieU, P. (1998): Contre-feux. Paris: Ed. Liber, Raison d'agir.

CASTEL, R. (1995): Les metamorphoses de la question sociale, une chronique du salariat. Paris: Ed. Fayard.

Combessie, P. (2001): Sociologie de la prison. Paris: Ed. La Découverte.

FoucAult, M. (1994): «La vie des hommes infames». Artículos en Dits et Ecrits, 1954-1988. Paris: Ed. Gallimard.

(1975): Surveiller et punir: Naissance de la prison. Paris: Ed. Gallimard, «Bibliotheque des Histoires».

GODEFROY T. y B. LAFFARGUE (1992): «Pauvreté, crime et prison», en L'actualité sociale, №194, La Documentation Francaise.

$-\mathrm{y}-(\mathrm{S} / \mathrm{F})$ : «Les couts du crime en France, les depenses de securité». Etudes et données penales $\mathrm{N}^{\circ} 66$, CESDIP.

IgnAtieff, M.: A Just Measure of Pain. The Penitentiary in the Industrial Revolution. New York: Pantheon Books.

MERINO, R. (2000): «Encierro, castigo y su relación con la prensa. 1970-2000». Tesis para optar a la licencia de ciencias sociales y jurídicas. Escuela de Derecho, Universidad de Chile.

WACQUANT, L. (1999): Les prisons de la misere. Paris: Ed. raisons d'agir. 